\title{
Seroprevalence and Risk Factors of Syphilis among Blood Donors
}

\author{
Sachin Singhal,' Sunita Rai,' Prakriti Gupta', Anita Arya', Dharmesh Chandra Sharma' \\ 'Blood Bank, Department of Pathology, G. R. Medical College and J. A. Groups of Hospital, Gwalior, India.
}

\begin{abstract}
Introduction

Transfusion of blood /component is an essential procedure in modern days of medical practice. As far as safe transfusion is concerned, it is a primary requirement i.e. handlesa transfusion transmitted infection (TTI) that is a virus, parasite, or other potential pathogen that can be transmitted in donated blood through a transfusion to a recipient.Focus of the present study is to assess seroprevalence and risk factors of Syphilis among blood donors in greater Gwalior
\end{abstract}

\section{Methods}

The present retrospective descriptive study was conducted over a period of 8 years. All the samples of voluntary and relative blood donors, who came to donate blood, were tested for transfusion transmissible infections. Prevalence of TTIs and syphilis were analyzed in the view of different parameters of donors and along with its associated risk factors.A chi square $\left(X^{2}\right)$ statistic is used to investigate whether distributions of categorical variables differ from one another.

\section{Results}

In the present study prevalence of TTIs is $3.44 \%$ and for syphilis it is $0.268 \%$, most common age group is $40-51$ years (41.18\%); male to female ratio is insignificant statistically. Ratio of voluntary versus relative donors was $94.21 \%$ and $5.79 \%$ respectively while maleversus female ratio of donors was $91.27 \%$ and $8.473 \%$ respectively.

\section{Conclusions}

An advance knowledge, attitude, and behavior of the volunteer blood donors' population regarding risk factors will most probably improve public health and increase blood safety and quality.

Keywords: Seroprevalence; Syphilis; Transfusion Transmitted Infections.

\section{INTRODUCTION}

Blood donation is an important procedure in the modern allopathic medical practice that saves millions of lives around universe. However, unsafe transfusions carry the risk of transfusiontransmissible infections (TTIs) and a consequence of that is very costly economically not only for

Correspondance: Dr. Dharmesh Chandra Sharma, Department of Pathology, G. R. Medical College and J. A. Groups of Hospital, Gwalior, India. Email: sharmadrdharmesh@gmail.com. Phone: +91-9425111202. 
the individuals but also for the community as a whole. Unsafe transfusions also hampered the physical and social status of an individual as well as the society. ${ }^{1,2}$ It is well-known that since historic times ${ }^{3,4}$ due to the significant increase in the number of cases diagnosed, syphilis has been an exceedingly important challenge for public health. ${ }^{5}$

Testing of hepatitis B virus (HBV), hepatitis C virus (HCV), human immunodeficiency virus (HIV) and Treponema palladium (TP) along with malarias is mandatory for all donations in India. Syphilis is a sexually transmitted disease (STD), which can also be transmitted via accidental direct inoculation, transplacental during pregnancy, and, rarely, via blood transfusion. ${ }^{6,7}$ The causative agent of syphilis is spirochete Treponema palladium, is a chronic, sexually transmitted infection and the estimated suffering of 36 million people worldwide, with 11 million new cases occurring annually. ${ }^{8}$

Syphilis is a multiphase disease intermingles by asymptomatic periods of latency. The primary syphilis present with a painless chancre in the initial stage of infection followed by secondary stage of a non-pruritic rash, which spontaneously resolve. ${ }^{9}$ The WHO (WorldHealth Organization) surveyed on the prevalence of four sexually transmitted diseases: Chlamydia trachomatis, Neisseria gonorrhoeae, syphilis, and trichomonas vaginalis and it was found that syphilis accounts for approximately $10 \%$ of these sexually transmitted diseases. ${ }^{10,11}$

Syphilis and HIV affect similar patient groups and co-infection is common. Syphilis Infection is a risk factor for $\mathrm{HIV}, \mathrm{HBV}$, and $\mathrm{HCV}$ infections. ${ }^{12-14}$ The risk factors for blood donors infected with syphilis are also risk factors for other blood borne diseases. ${ }^{15-17}$ Screening for high-risk groups before blood donation currently depends entirely on pre-donation health consultation.
They can donate blood or need postpone and withdraw from blood donation is depend on the report of blood donors on medical history and dangerous behavior. ${ }^{18,19}$

Blood donation in high-risk groups is a threat to blood safety. It is a matter of concern whether the high-risk group of blood donors is effectively excluded from the health consultation before blood donation. ${ }^{20}$

In many parts of the world, the incidence and prevalence of syphilis still remain high in both volunteer and family/replacement blood donors. ${ }^{21-26}$ There are numerous reports in high-risk groups in the literature, both from developed and developing countries, indicating rising prevalence and incidence of syphilis. ${ }^{27-31}$

Present study is accomplished to know the Seroprevalence of syphilis in and around the greater Gwalior and the risk factors accountable for the disease among the blood donors and in a population as awhole.

\section{METHODS}

The retrospective descriptive study was conducted in Blood Bank, Department of Pathology, G. R. Medical College, and Gwalior, India from 1st January 2012 to 31st December 2019 (8 years). Blood samples were collected from the blood donors/ Blood units, who came to donate blood in Blood Bank/ or in voluntary blood donation camps for TTIs (TransfusionTransmitted Infections). Blood donations from individuals suspicious for TTI diseases/ or from a high risk groups were deferred. Moreover the donors were pre counseled, examined for their health status and also fill out a donor screening registration form as a part of a routine blood donation screening procedure. Informed consent was obtained from all the donors. All five tests, mandatory for each and every donor/or blood units i.e. HIV 1 and 2, HCV, HbsAg, VDRL and Malaria were 
performed in our TTIs laboratory. For these tests, procedures were used as per guidelines of Food and Drug Administration, Government of India.For syphilis: - : Rapid Plasma Reagin (RPR) and RAPIKIT was used (Make -Span diagnostics and Lifescience limited).

All tests were performed according to manufactures instructions. The tests results were reported and the Seroprevalenceof TTIs and Syphilis were calculated. All the reactive samples were repeated in duplicate before labeling them seropositive. As a Protocol, serovigilance for tests was under monitoring of State Reference Laboratory (SRL), Department of Microbiology, G. R. Medical College, Gwaliorfor confirmation and quality control.The blood units/ samples were discarded as per guidelines of NACO whenever the pilot donor samples were found positive for any TTI.

Data has been collected, tabulated,summarized and compared statistically by frequency distribution and percentage proportion. A chi square $\left(X^{2}\right)$, Goodness of fit (One Sample Test) allows us to compare a collection of categorical data with some theoretical expected distribution. Statistic is used to investigate whether distributions of categorical variables differ from one another.

\section{RESULTS}

During the study period 146032 Blood units were collected from healthy donors ageing 18

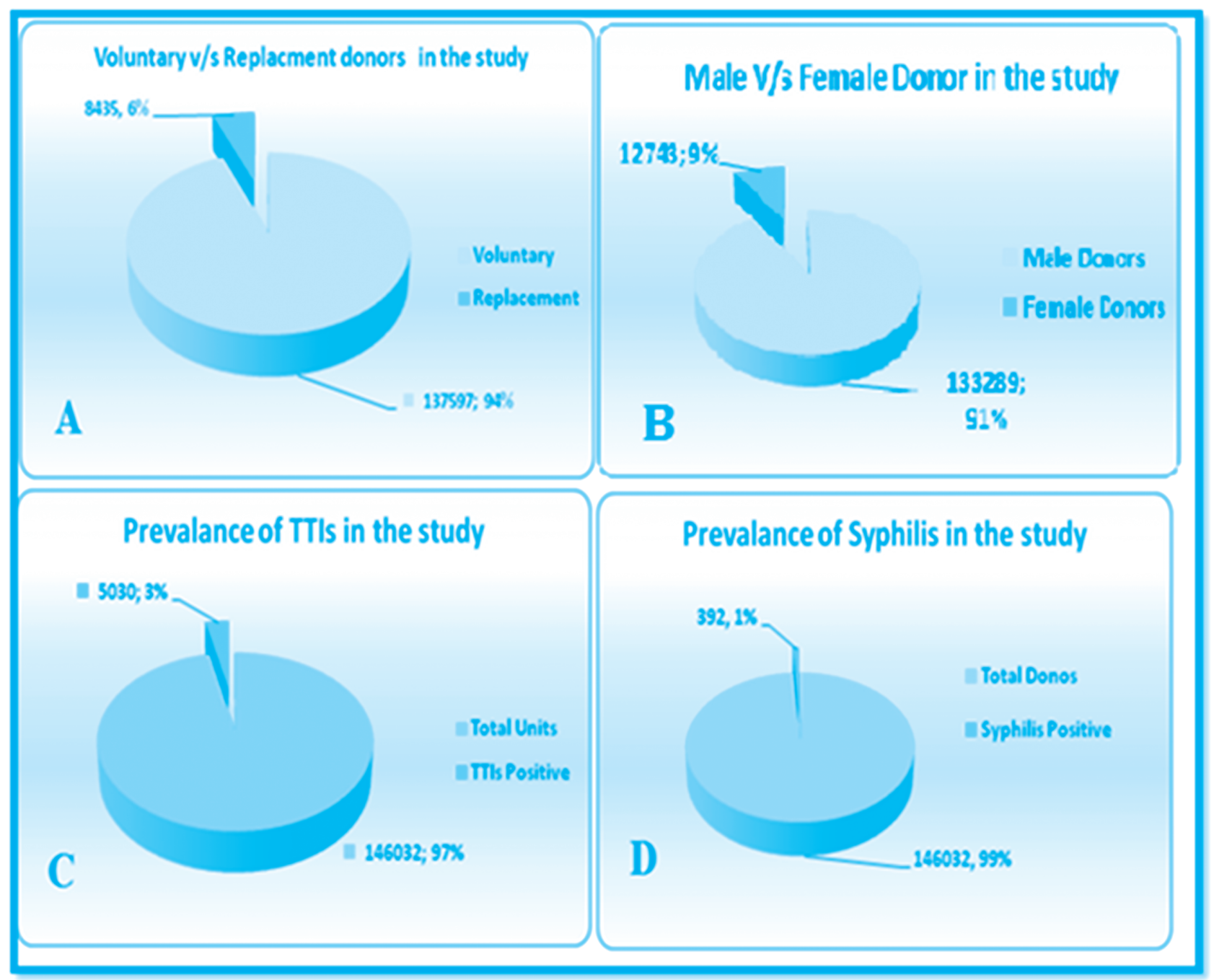

Figure 1. Voluntary v/s related Donors. B: Male v/s Female Donors. C: Prevalence of TTIs. D: Prevalence of Syphilis. 
to 60 years. Out of 146032 units, 133289 (91.27\%) were male and $12743(8.473 \%)$ were female donors while ratio of voluntary versus relative donors was $94.21 \%(n=137597)$ and $5.79 \%(n=$ 8435) respectively and data's are statistically significant ( $p=0.000001)$ (Figure $1 \mathrm{~A}$ and $1 \mathrm{~B})$.

Yearly distribution of TTIs and syphilis was shown in Figure 2 and Table 1. Out of 146032 donors, $5030(3.44 \%)$ were found reactive and 141002 (96.56\%) were non reactive for transfusion transmitted infection (TTIs) in last eight years since year 2012 t0 2019 and the prevalence of syphilis was found in 392 cases which was $0.268 \% \quad(n=392 / 146032)$ in total donors and $7.79 \%$ was among total 5030
TTIs positive donors (392/5030). Comparison of prevalence rate of TTI and Syphilis according to year wise was found statistically significant $(p=.000001)$ after analysis with chi square; Goodness of fit statistical test applied. (Table 1 and Figure $1 \mathrm{C}$ and D). Prevalence of syphilis in male was found in 355 (90.56\%) in comparison to females there was only 37 cases $(9.44 \%)$ but male female ratio of positivity was found 48:52 i.e. more or less similar and which is not statistically significant $(p=0.689)$. Out of 392 seropositive cases for syphilis, 18 (4.5\%) cases were have multiple TTIs infection (5 cases were $\mathrm{HIV} \& \mathrm{HbsAg}, 10$ cases for HbsAg and 3 cases of $\mathrm{HCV}$ ).

Table 1. Prevalence of TTls and syphilis in the study period

\begin{tabular}{|c|c|c|c|}
\hline \multirow{2}{*}{ Year } & \multirow{2}{*}{ Total Units Tested } & TTI Positive Units & VDRL Positive units \\
\hline & & No $(\%)$ & $\mathrm{No}(\%)$ \\
\hline 2012 & 14001 & $575(4.11)$ & $54(9.39)$ \\
\hline 2013 & 14473 & $526(3.63)$ & $50(9.50)$ \\
\hline 2014 & 15761 & $511(3.24)$ & $28(5.48)$ \\
\hline 2015 & 16630 & $613(3.68)$ & $26(4.24)$ \\
\hline 2016 & 18297 & $715(3.91)$ & $79(11.05)$ \\
\hline 2017 & 20500 & $717(3.50)$ & $98(13.67)$ \\
\hline 2018 & 23941 & $726(3.02)$ & $24(3.30)$ \\
\hline 2019 & 22429 & $647(2.88)$ & $33(5.10)$ \\
\hline Total & 146032 & $5030(3.44)$ & $392(7.79)$ \\
\hline P Value & $d f=7$ & $X^{2}=83.62 *,(p=0.000001)^{* *}$ & $X^{2}=105.67^{*},(p=0.000001)^{* *}$ \\
\hline \multicolumn{4}{|c|}{ * $X^{2}$ value calculated by Goodness of fit } \\
\hline
\end{tabular}

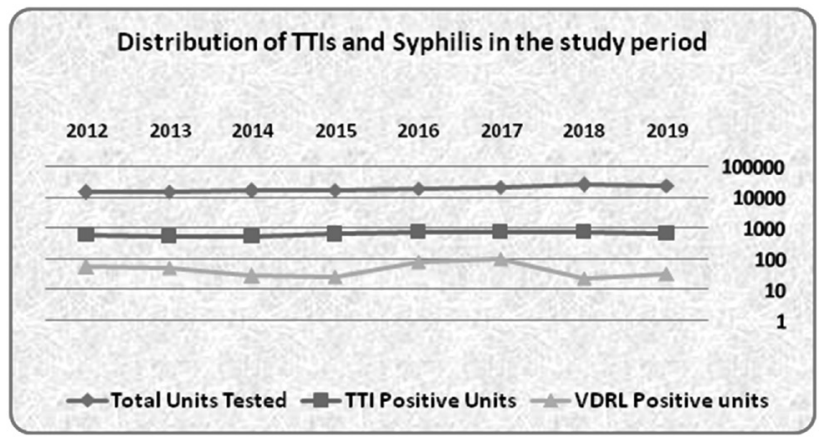

Age group distribution of donors in the study and prevalence of TTIs and syphilis among different age groups was shown in table No. 2 and it's data distribution is statistically significant $(\mathrm{P}=.000001)$.

Figure 2. Yearly distribution of TTls and syphilis in the study 


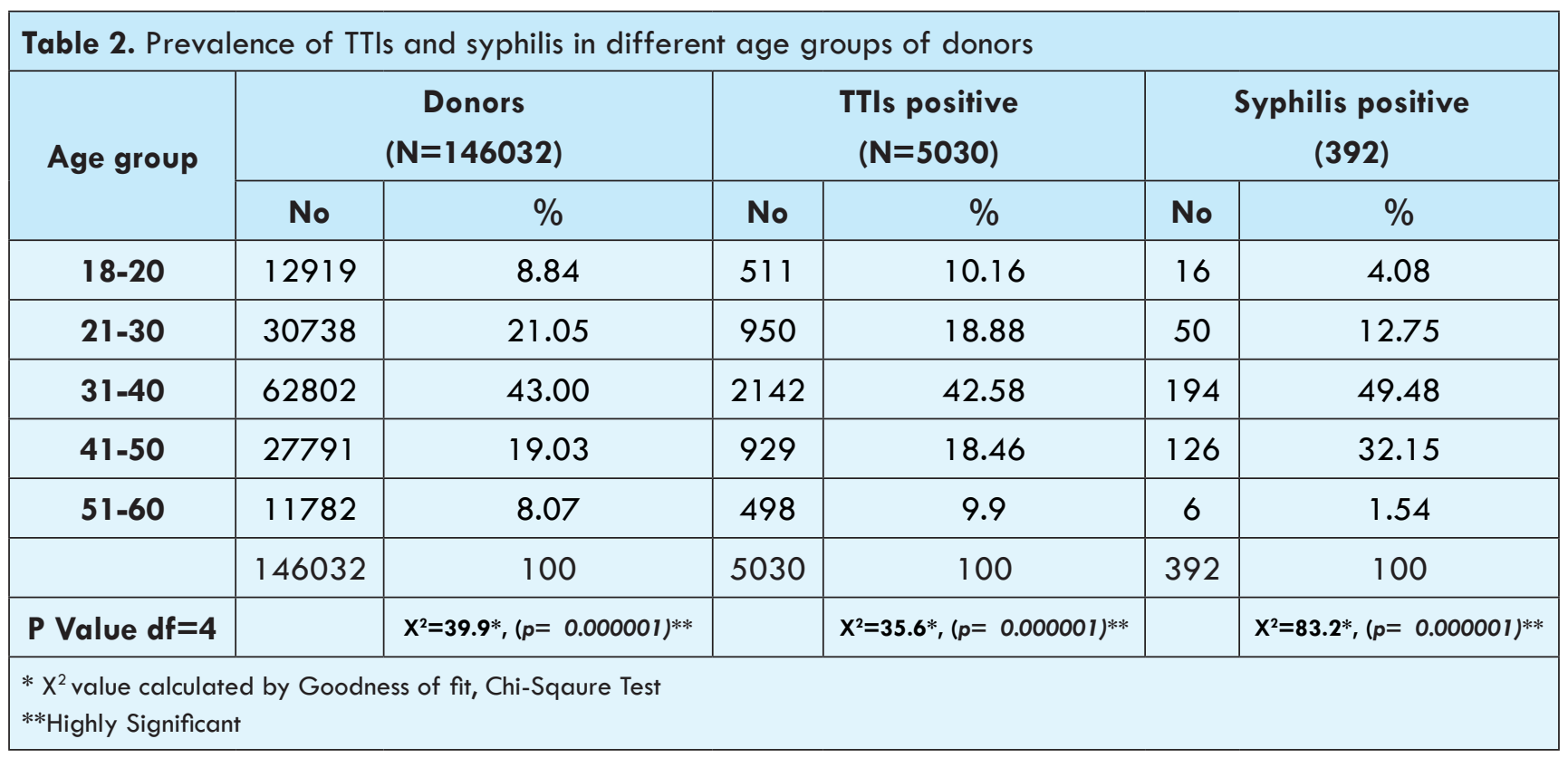

\section{DISCUSSION}

In the present study the overall Seroprevalence of TTIs and syphilis is $3.44 \%(n=5030 / 146032)$ and $0.268 \%(n=392 / 146032)$ respectively while Seroprevalence of syphilis among total 5030 TTIs is $7.79 \%(392 / 5030)$.

The blood donors are suppose to be a selective population, since they are pre-screened for past diseases and sexual behavior by the detailed questionnaire and personal interview before donation. However, presently blood donation is performed by all citizens between the age group of 18- 60 years; it could provide general picture regarding incidence and prevalence of syphilis in these population.

Presently the safety of transfusions has reached a very high level almost in every corner of the world. Still, some remaining risks of TTI are there and no blood/component is $100 \%$ safe. The susceptible population of syphilis is the same one as for HIV, with alike biological and behavioral factors. ${ }^{32} \mathrm{~A}$ similar situation exists in the infection of HBV and HCV. Risk factors for blood donors infected with syphilis are also risk factors for other blood-borne diseases. ${ }^{33,34}$

The prevailing views is that syphilis is a sexually transmitted disease but shared razors, ear piercings, and tattoos are also the high risk factors for syphilis infection. Currently, cosmetic surgery such as tattooing, piercing, rhinoplasty, injection, laser, and liposuction has greatly increased. Therefore, the blood transmits pathway of syphilis should not be ignored. . $^{35,36}$

In the present time sexual consciousness are more open andincreasing population of multisex partners has a significant risk factor for syphilis infection. In many countries blood donor selection requirements clearly stipulates that multiple sexual partners and heterosexuals cannot donate blood. ${ }^{37,38}$ However, there are still some blood donors who deliberately hide the facts of their multiple sexual partners and heterosexuality and enterthe blood donation process on false statements. It may be duethe fact that some blood donors worried about privacy disclosures when blood was collected in the open environment of voluntary blood donation camps.

This study identified that the overall prevalence of syphilis seropositivity among nearly 146032 blood donors in 2012-2019 was 268.4 per 100 000 , which was higher than that reported in the 
USA (54.6 per 100 000) and Brazil (135.5 per 100 $000)^{39-41}$ but lower than that reported in Ethiopia (732.4 per 100 000) and Cameroon (3976.3 per 100 000). ${ }^{42,43}$ The disparity in the prevalence of syphilis observed in different studies may be due to geographical differences in the prevalence of syphilis as well as some methodological differences. It has been earlier reported that $T$. pallidum particle agglutination assay are more sensitive than rapid plasma reagin and $T$. palladium hem-agglutination assay. ${ }^{44}$

In the present study we found that the prevalence of syphilis was slightly more in female than male (male $48 \%$ and female $52 \%$ ) which is similar as reported byVera L. et al, ${ }^{45}$ whodemonstrates that the prevalence of Syphilis was almost similar in both male and female which was 45 and 49 per 100,000 respectively. How so ever it is statistically not significant ( $p=0.689157)$ in the present study.

In our study the most common age-group affected by syphilis was $41-50$ years $(41.18 \%)$ followed by age group 31-40 (28.09\%) ,21-30 $(14.82 \%), 18-20(11.27 \%),>51(4.64 \%)$ while it was 45 years and older in the study done by Vera L. et al. ${ }^{45}$ This study found that syphilis prevalence significantly higher in mature adults age 41-50, so more importantly, based on the results of this study and previous studies, health awareness and syphilis prevention programs focusing on mature adults is needed.

The association of syphilis with other TTIs is $4.5 \%$ ( $n=18 / 392$ cases) in the present. It is for Syphilis- HIV is $1.27 \%$ (n-5/392), Syphilis HbsAg $2.55 \%(n=10 / 392)$ and for Syphilis- HCV o.67\% $(n=3 / 392)$. Several studies had also reported coinfections HBV-Syphilis and HIV-Syphilis as commonly encountered one. ${ }^{44,46,47,48}$ The possible reason for the occurrence of co-infections could be because these pathogens share common modes of transmission and risk groups.

Advance tests for TTIs, confirmatory test for the syphilis and better donor motivation, recruitment and retention strategies along with public awareness of voluntary blood donation should be implemented to increase the blood safety.

\section{Limitations of this study}

1. The rapid screening testkits used for this study arevitro qualitative methods, not a confirmative one. However, positivity of Syphilis could not be further validated by confirmatory tests.

2. No information on syphilis Seroprevalence between first-time donors and repeat donors is also a limitation to this study.

\section{CONCLUSIONS}

In our study prevalence of syphilis is moderate $(0.268 \%)$ in comparison to; low prevalence was reported from developed countries while higher prevalence is prevailing in under developed and African countries. Common age group prevalence in our study was 41-50 years. Male to female distribution is statistically insignificant. An advance knowledge, attitude, and behavior of the volunteer blood donors' population regarding risk factors will most probably improve public health and increase blood safety and quality.

\section{ACKNOWLEDGMENTS}

Author(s) are thanks full to Professor Dr. Anil Agrawal, Head of the department of Preventive and Social Medicine, G. R. Medical College, Gwalior for providing us the statistical analysis support for this paper.

\section{Consent}

The authors declare that written informedconsent wasobtained from thepatients before being recruited for this research.

\section{Ethical Approval}

All author(s) hereby declare that all procedure 
have been examined and approved by the appropriate ethics committee of Gajra Raja Medical College, Gwalior, India(Reference No. 589/Bio/Ethical/ MC ) and research have therefore been performed in accordance with

\section{REFERENCES}

1. Greinacher A, Weitmann K, Schonborn L, et al. A population-based longitudinal study on the implication of demographic changes on blood donation and transfusion demand. Blood advances. 2017;1(14):867-874. doi: 10.1182/bloodadvances.2017005876.

2. Yu C, Holroyd E, Cheng Y, Lau JT. Institutional incentives for altruism: gifting blood in China. BMC Public Health. 2013;13:524. doi: 10.1186/14712458-13-524.

3. Rovesti M. Between history and gossip: the state of women relative to syphilis, a traditionally male disease. $J$ BiolRegulHomeost Agents.2017; 31: 187191

4. SarkodieF . Syphilis screening practices in blood transfusion facilities in Ghana. Int J Infect Dis. 2016; 43: 90-94.

5. Hook EWR. Syphilis. Lancet. 2017; 389: 1550-1557.

6. E. Van Dyck, R. Musonda, L. Zekeng et al., "Study Group on Heterogeneity of HIV Epidemics in Zeltser R, Kurban AK. Syphilis," Clinics in Dermatology, vol. 22, pp. 461-468, 2004.

7. C. Gardella, A. A. Marfin, R. H. Kahn, E. Swint, and L. E. Markowitz. Persons with early syphilis identified through blood or plasma donation screening the ethical standards laid down in the 1964 declaration of Helsinki.

\section{Competing Interests}

Authors have declared that no competing interests exist.

in the United States. Journal of Infectious Diseases. 2009 ; 185(4), 545-549.

8. Lafond RE, Lukehart SA. Biological basis for syphilis. ClinMicrobiol Rev. 2006;19(1):29-49. doi: 10.1128/ CMR.19.1.29-49.2006.

9. Brigette C, Erika W, John R W, Caroline E C. Interaction of Treponema pallidum, the syphilis spirochete, with human platelets. Treponema pallidum-platelet interactions. Jan 18, 2019;14(1):e0210902.

10. Rolfs RT. Treatment of syphilis. Clinical infectious diseases: an official publication of the Infectious Diseases Society of America. Apr. 1995;20(Suppl 1):S23-S38.

11. Kitayama K, Segura ER, Lake JE, et al. Syphilis in the Americas: a protocol for a systematic review of syphilis prevalence and incidence in four highrisk groups, 1980-2016. Systematic reviews. 2017;6(1):195. doi: 10.1186/ s13643-017-0595-3.

12. Borobio MV. Syphilis and HIV infection. EnfermInfecc MicrobiolClin. 1990;8 (1):7

13. Vahdani P, Hosseini-Moghaddam SM, Family A, Moheb-Dezfouli R. Prevalence of HBV, HCV, HIV and syphilis among homeless subjects older than fifteen years in Tehran. Arch Iran Med. 2009;12(5):483487. 
14. Offergeld R, Ritter S, Hamouda O, HIV $\mathrm{HCV}$. HBV and syphilis surveillance among blood donors in Germany 2008-2010. Bundesgesundheitsblatt, G e s u n d h e it s f o r s c h u n g, Gesundheitsschutz. 2012 ;55(8):907-913. doi: 10.1007/s00103-012-1516-1.

15. Yang $\mathrm{T}$, Chen $\mathrm{Q}$, Li D, et al. High prevalence of syphilis, $\mathrm{HBV}$, and $\mathrm{HCV}$ co-infection, and low rate of effective vaccination against hepatitis $\mathrm{B}$ in HIV-infected patients in West China hospital. J Med Virol. 2018;90(1):101108. doi: 10.1002/jmv.24912.

16. Salado-Rasmussen K. Syphilis and HIV co-infection. Epidemiology, treatment and molecular typing of Treponema pallidum. Danish medical journal. Dec 2015;62(12):B5176.

17. Niama FR, LoukabouBongolo NC, Mayengue PI, et al. A study on HIV, Syphilis, and hepatitis $B$ and $C$ virus infections among female sex workers in the republic of Congo. Archives of public health $=$ archives belges de santepublique. 2017;75:21. doi: 10.1186/ s13690-017-0189-5.

18. Wiesen B, Kramer H, Meurer A, Stohr C. Ambulatory preoperative autologous blood donation using the leap frog procedure. A report of experiences. Der Chirurg; Zeitschrift fur alleGebiete der operativenMedizen. 1988;59(9):620-622.

19. Manuel SP, Spitzer TR, Ishizawa Y. Preoperative autologous blood donation in healthy bone marrow donors contributes to preprocedure anemia. Bone Marrow Transplant. 2017;52(8):1191-1193. doi:

\subsection{8/bmt.2017.84.}

20. . Shuangli Liu, Liping Luo, Guangxiang Xi, Like Wan, Li Zhong, Xue Chenet al. Seroprevalence and risk factors on Syphilis among blood donors in Chengdu, China from 2005 to 2017. BMC Infect Dis. 2019; 19: 509. Published online 2019 Jun 10. doi: 10.1186/s12879019-4128-7PMCID:

PMC6558839. PMID: 31182042

21. M. L. K. Mogtomo, S. L. Fomekong, H. F. Kuate, and A. N. Ngane. Screening of infectious microorganisms in blood banks in Douala (1995-2004). Cahiers Sante. 2009; 19(1), 1-8.

22. S. Zou, E. P. Notari, C. T. Fang, S. L. Stramer, and R. Y. Dodd. Current value of serologic test for syphilis as a surrogate marker for blood-borne viral infections among blood donors in the United States. Transfusion.2009; 49(4).655-661.

23. J. Liu, Y. Huang, J. Wang et al. The increasing prevalence of serologic markers for syphilis among Chinese blood donors in 2008 through 2010 during a syphilis epidemic. Transfusion. 2012; 52, 1741-1749.

24. Z. H. Ji, C. Y. Li, Y. G. Lv et al. The prevalence and trends of transfusiontransmissible infectious pathogens among first-time, voluntary blood donors in Xi'an, China between 1999 and 2009. International Journal of Infectious Diseases 2013; 17, 259-262.

25. J. J. Noubiap, W. Y. Joko, J. R. Nansseu, U. G. Tene, and C.Siaka. Sero-epidemiology of human immunodeficiency virus, hepatitis B and C viruses, and syphilis 
infections among first-time blood donors in Edéa, Cameroon. International Journal of Infectious Diseases. 2013;17,832-837.

26. S. L. Gottlieb, V. Pope, M. R. Sternberg et al. Prevalence of syphilis seroreactivity in the United States: Data from the National Health and Nutrition Examination Surveys (NHANES) 20012004. Sexually Transmitted Diseases. 2008; 35 (5),507-511.

27. Department of Health and Human Services CfDCaP National Center For HIV, STD and TB Prevention, Division of STD Prevention, 2005.

28. P. Pathela, S. L. Braunstein, J. A. Schillinger, C. Shepard, M. Sweeney, and S. Blank. Men who have sex with men have a 140-fold higher risk for newly diagnosed HIV and syphilis compared with heterosexual men in New York City. Journal of Acquired Immune Deficiency Syndromes. 2011 ; 58 (4), 408-416.

29. Salado-Rasmussen K, Katzenstein TL, Gerstoft J, Cowan SA, Knudsen TB, Mathiesen L, Hoffmann S, Obel N. Risk of HIV or second syphilis infection in Danish men with newly acquired syphilis in the period 2000-2010. Sex Transm Infect. 2013 Aug;89(5):372-6. doi: 10.1136/sextrans-2012-050580. Epub 2012 Dec 27. PMID: 23270933.

30. Muldoon E, Mulcahy F. Syphilis resurgence in Dublin, Ireland. Int J STD AIDS. 2011 Sep;22(9):493-7. doi: 10.1258/ ijsa.2011.010438. PMID: 21890544.

31. Hao C, Yan H, Yang H, Huan X, Guan W, Xu X, Zhang M, Tang W, Wang N, $\mathrm{Gu}$ J, Lau JT. The incidence of syphilis,
HIV and HCV and associated factors in a cohort of men who have sex with men in Nanjing, China. Sex Transm Infect. 2011 Apr;87(3):199-201. doi: 10.1136/sti.2010.042903. Epub 2011 Jan 24. PMID: 21262785.

32. Lynn WA, Lightman S. Syphilis and HIV: a dangerous combination. Lancet Infect Dis. 2004;4(7):456-466. doi: 10.1016/S1473-3099(04)01061-8.

33. McQuillan GM, Townsend TR, Fields HA, Carroll M, Leahy M, Polk BF. Seroepidemiology of hepatitis B virus infection in the United States. 1976 to 1980. Am J Med. 1989;87(3A):5S-10S. doi: 10.1016/0002-9343(89)90523-8.

34. Low E, Vogel M, Rockstroh J, Nelson M. Acute hepatitis C in HIV-positive individuals. AIDS reviews OctDec. 2008;10(4):245-253.

35. Gillen MM, Dunaev J. Body appreciation, interest in cosmetic enhancements, and need for uniqueness among U.S. college students. Body image. 2017;22:136-143. doi: 10.1016/j. bodyim.2017.06.008.

36. Ng JH, Yeak S, Phoon N, Lo S. Cosmetic procedures among youths: a survey of junior college and medical students in Singapore. Singap Med J. 2014;55(8):422-426. doi: 10.11622/ smedj.2014100.

37. Zheng $X$, Ding $W, L i \quad G$, et al. Seroprevalence of transfusiontransmissibleinfectious agents among volunteer blood donors between 2006 and 2012in Zhejiang, China [J]. Blood Transfus. 2015;13(3):1-10.

38. Schmidt AJ, Marcus U. Erratum to: 
deficits inSTI diagnosis for men whohave sexwithmen(MSM)inGerman-speaking cities [J].Bundesgesundheitsblatt G e s u n d h e i t s f o r s c h u n g Gesundheitsschutz. 2014;57(3):388-9. (5) (PDF) Seroprevalence and risk factors on Syphilis among blood donors in Chengdu, China,from 2005 to 2017.

39. Kane MA ,Bloch EM, Bruhn R, et al. Demographic determinants of syphilis seroprevalence among U.S. blood donors, 2011-2012. BMC Infect Dis 2015;15:63.doi:10.1186/s12879-0150805-3

40. Vera L, Milka D, Nurith S-L, et al. Prevalence and incidence of syphilis among volunteer blood donors in Israel. Journal of Blood Transfusion 2014;2014:1-7. doi:10.1155/2014/154048

41. Baião AM , Kupek E , Petry A . Syphilis seroprevalence estimates of SANTA Catarina blood donors in 2010. Rev Soc Bras Med Trop 2014;47:179-85. doi:10.1590/0037-8682-0032-2014

42. Abate $\mathrm{M}$, Wolde $\mathrm{T}$. Seroprevalence of human immunodeficiency virus, hepatitis B virus, hepatitis $C$ virus, and syphilis among blood donors at Jigjiga blood bank, eastern Ethiopia. Ethiop J Health Sci 2016;26:153-60.doi:10.4314/ ejhs.v26i2.9

43. Dionne-Odom J, Mbah R ,Rembert NJ, et al . Hepatitis B, HIV, and syphilis seroprevalence in pregnant women and blood donors in Cameroon. Infect Dis ObstetGynecol 2016;2016:1-8.

\section{doi:10.1155/2016/4359401}

44. Tessema B, Yismaw G, Kassu A, et al. Seroprevalence of $\mathrm{HIV}, \mathrm{HBV}, \mathrm{HCV}$ and syphilis infections among blood donors at Gondar University teaching hospital, Northwest Ethiopia: declining trends over a period of five years. BMC Infect Dis. 2010;10:111

45. Vera L, Milka D., Nurith S L, and Shinar Eilat S. 2014“Prevalence and Incidence of Syphilis among Volunteer Blood Donors inIsrael"Journal of Blood Transfusion Volume 2014 । ArticleID 154048 | 7 pages | https://doi. org/10.1155/2014/154048

46. Nagalo MB, Sanou M, Bisseye C, Kaboré MI, Nebie YK, Kienou K. Seroprevalence of human immunodeficiency virus, hepatitis $B$ and $C$ viruses and syphilis among blood donors in Koudougou (Burkina Faso) in 2009. Blood Transfus. 2011;9:419-24. pmid:21839011

47. Biadgo B, Shiferaw E, Woldu B, Alene KA, Melku M. Transfusion-transmissible viral infections among blood donors at the North Gondar district blood bank, northwest Ethiopia: A three year retrospective study. PloS one. 2017;12(7):e0180416. pmid:28678865

48. Teklemariam Z, Mitiku H, Weldegebreal F. Seroprevalence and trends of transfusion transmitted infections at Harar blood bank in Harari regional state, Eastern Ethiopia: eight years retrospective study. BMC hematology. 2018;18(24).

Citation: Singhal S, Rai S, Gupta P, Arya A, Sharma D. Seroprevalence and Risk Factors of Syphilis among Blood Donors. JCMS Nepal. 2021; 17(2); 185-94. 